\title{
Social Support Patterns of Middle-Aged and Older Adults Within a Physical Activity App: Secondary Mixed Method Analysis
}

Zakkoyya H Lewis $^{1 *}$, PhD, ATC, ACSM EP-C; Maria C Swartz ${ }^{2 *}$, MPH, PhD, RD, LD; Eloisa Martinez ${ }^{3}$, BS; Elizabeth J Lyons ${ }^{4}, \mathrm{MPH}, \mathrm{PhD}$

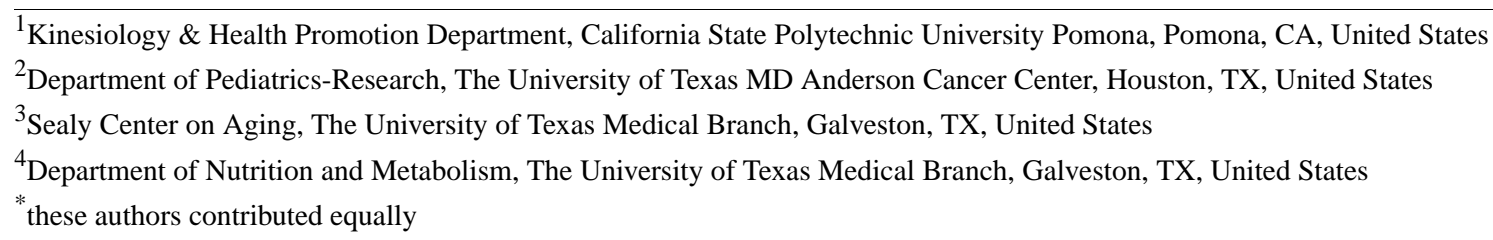

Corresponding Author:

Maria C Swartz, MPH, PhD, RD, LD

Department of Pediatrics-Research

The University of Texas MD Anderson Cancer Center

1515 Holcombe Blvd

Houston, TX, 77030-4009

United States

Phone: 17137453763

Fax: 17135635406

Email: mchang1@mdanderson.org

\section{Abstract}

Background: Physical activity (PA) is critical for maintaining independence and delaying mobility disability in aging adults. However, 27 to $44 \%$ of older adults in the United States are meeting the recommended PA level. Activity trackers are proving to be a promising tool to promote PA adherence through activity tracking and enhanced social interaction features. Although social support has been known to be an influential behavior change technique to promote PA, how middle-aged and older adults use the social interaction feature of mobile apps to provide virtual support to promote PA engagement remains mostly underexplored.

Objective: This study aimed to describe the social support patterns of middle-aged and older adults using a mobile app as part of a behavioral PA intervention.

Methods: Data from 35 participants (mean age 61.66 [SD 6] years) in a 12-week, home-based activity intervention were used for this secondary mixed method analysis. Participants were provided with a Jawbone Up24 activity monitor and an Apple iPad Mini installed with the UP app to facilitate self-monitoring and social interaction. All participants were given an anonymous account and encouraged to interact with other participants using the app. Social support features included comments and likes. Thematic coding was used to identify the type of social support provided within the UP app and characterize the levels of engagement from users. Participants were categorized as superusers or contributors, and passive participants were categorized as lurkers based on the literature.

Results: Over the 12-week intervention, participants provided a total of 3153 likes and 1759 comments. Most participants $(n=25)$ were contributors, with 4 categorized as superusers and 6 categorized as lurkers. Comments were coded as emotional support, informational support, instrumental support, self-talk, and other, with emotional support being the most prevalent type.

Conclusions: Our cohort of middle-aged and older adults was willing to use the social network feature in an activity app to communicate with anonymous peers. Most of our participants were contributors. In addition, the social support provided through the activity app followed social support constructs. In sum, PA apps are a promising tool for delivering virtual social support to enhance PA engagement and have the potential to make a widespread impact on PA promotion.

Trial Registration: ClinicalTrials.gov NCT01869348; https://clinicaltrials.gov/ct2/show/NCT01869348

(JMIR Aging 2019;2(2):e12496) doi: $\underline{10.2196 / 12496}$ 


\section{KEYWORDS}

social support; aged; middle aged; physical activity; technology; fitness tracker

\section{Introduction}

\section{Physical Activity and Social Support}

Physical activity (PA) is critical during the aging process to help maintain independence and delay the development of mobility disability. Yet, in a study conducted by Keadle et al in 2016 , less than $50 \%$ of healthy older adults achieved the recommended PA level [1]. In fact, research has found that adherence to PA guidelines or interventions decreased from $80 \%$ to $50 \%$ over 12 months [2]. Traditional PA interventions are labor intensive for both the research team and the participants. Recent advances in technology have produced methods (eg, wearable activity trackers) that allow for less labor-intensive PA intervention design [3]. Wearable activity trackers have been shown to be a promising tool to augment traditional PA intervention designs by replacing the need to manually record PA through passive activity tracking [3]. Activity trackers also expand on limited feedback of pedometers by providing goal-setting assistance and extensive feedback on progress and encouraging social interaction [4]. Despite a surge in the use of activity trackers within PA interventions, it is not yet clear how middle-aged and older adults use the virtual support features to promote PA engagement. Given that social support is a psychosocial factor that has been consistently identified as a critical factor for the adoption and maintenance of PA behavior [5,6], it is important for us to examine this influential psychosocial factor to provide insight for future PA intervention designs.

Social support is defined as an interpersonal exchange that increases self-esteem and offers acceptance, value, and motivation to individuals [7]. In a study, individuals who perceived low social support within their social environment were found to be 2 times more likely to be sedentary [8]. Reviews have indicated that shared experience, such as exercising in a group setting (eg, walking club) or being socially connected (eg, community facilities or virtual blogs), can help shape and foster the adoption of PA behavior [9]. Furthermore, empirical evidence has indicated that social support is an influential behavioral change technique that has the potential to encourage PA among older adults $[6,10,11]$ and promote adherence to PA recommendations [5,12]. Using the self-determination theory (SDT) as the framework [13], Vallerand posited that social support can affect the degree of motivation (also referred to as the degree of self-determination) and, in turn, affect health behavior [14]. George et al explored the mechanistic relationship further by using the hierarchical model of intrinsic and extrinsic motivation models and found that perceived social support positively associated with the 3 components of basic psychological needs (autonomy, competence, and relatedness) as indicated by SDT $[13,15]$. In turn, the psychological needs were positively associated with motivation and PA intention [15]. Thus, we can posit that social support plays a critical role in meeting the basic psychological needs and, in turn, increases motivation to engage in PA.

\section{Social Support Constructs}

Constructs of social support, through social media or conventional means, can be categorized as emotional, informational, instrumental, or appraisal support as described by Heaney and Israel [16]. Emotional support is an expression of empathy, love, trust, or care. Informational support provides advice or information. Instrumental support provides tangible aid. Appraisal support provides information that is useful for self-evaluation [16]. Support can also come from within the individual through self-talk $[17,18]$. Self-talk can be a discussion with oneself or a multiparty dialog [17], and it can be positive or negative among individuals [18]. With the increase in mobile phone usage and wearable activity tracker usage, individuals seeking support can do so using social networks available in mobile apps. Research shows that social networking sites (SNSs) have been used to provide informational support (eg, guidance), instrumental support (eg, connect individuals with resources), and emotional support. In addition, SNSs have also been used to facilitate behavior change interventions [16,19-22]. Specifically, de la Peña and Quintanilla found that health-related Facebook communities were able to provide informational, instrumental, and emotional support needed for members to achieve their goals [20] through features such as likes and comments [20]. The like feature is a form of emotional support by providing users positive and indirect feedback. The comments feature in itself is a form of emotional support. However, it is also used to provide appraisal support (ie, constructive feedback) or instrumental and/or informational support (ie, suggestions or connection with resources).

Nevertheless, individuals vary in how they participate in SNSs to receive and provide social support. Researchers confirmed that the 90-9-1 principle (also known as the $1 \%$ rule) developed by digital marketing researchers [23] also reflected the phenomenon observed within the digital health environment [24]. Researchers found that content came within the digital health SNSs or the internet support groups came from superusers and contributors [24-26]. Most content was provided by superusers who represent approximately $1 \%$ of the members in the SNSs. Contributors generated a minority of the content, and they represent about $9 \%$ of the members. Most members in the digital health support system are considered as lurkers ( 90\%). These are individuals who observe without active participation [27-29].

\section{Objective}

Although the popularity of receiving and providing social support through SNSs is rising, the usage pattern for health and PA promotion among middle-aged and older adults remains unclear [30]. There is preliminary evidence that older adults who use virtual support provide comments that align within the constructs of social support [31], but they are cited as being apprehensive about communicating with strangers [32] although an increasing number of older adults are on social media sites [33]. Thus, the purpose of this secondary data analysis was to describe the social support patterns among middle-aged and 
older adults using a mobile phone app as part of a behavioral PA intervention and evaluate them within the constructs of social support. We hypothesize that social support patterns in our cohort of middle-aged and older adults will align with the social support constructs and social network engagement pattern.

\section{Methods}

\section{Study Design and Population}

This study was a secondary mixed-method analysis with data retrieved from a randomized controlled study (Trial Registration: NCT01869348). Data were drawn from a 12-week, randomized controlled behavioral PA study. The primary study's recruitment and intervention methods are published elsewhere [34]. The eligibility criteria were as follows: (1) aged 55 to 79 years, (2) body mass index of 25 to $35 \mathrm{~kg} / \mathrm{m}^{2}$, (3) able to read and understand English, (4) able to read the print off of a tablet, and (5) cleared to participate as determined by the Physical Activity Readiness Questionnaire [35]. Participants were enrolled and started the intervention between 2014 and 2016. This secondary analysis included 35 of the 40 study participants who used the UP app (Jawbone, San Francisco, CA) and who always had at least one participant (herein referred to as peers) to communicate with during the week. Due to rolling enrollment, the actual number of peers fluctuated on a weekly basis (between 0 and 10). Of the 40 participants, 5 were not included in this analysis because they either refused to participate in the intervention after the wait-list period or did not have at least one peer to communicate with during any point of the intervention.

\section{Procedures}

Eligible participants were randomized to either the intervention group or the wait-list control group. The intervention provided a wearable activity monitor (UP24 by Jawbone, San Francisco, CA) and a mobile tablet device (iPad Mini by Apple, Cupertino, CA) and received scripted, brief weekly telephone cognitive behavioral counseling. The wait-list control group received all the intervention components after their 12-week final assessment. The UP app was preinstalled on the tablets so that the participants could view their activity and interact with other participants. All participants were given an anonymous account (eg, Monopoly icons) and were friended with the other participants and the interventionists. Interventionists used the app for surveillance of the participants only unless there was a software update. The participants were encouraged, but not required, to socialize with others. Participants were instructed to ignore friend requests from unknown users. The app posted individual entries for each person and their peers' activity progress daily in the news feed. Participants were able to comment and like the entries; these interactions were analyzed to estimate social support. Interactions were categorized as received and given support based on whether a comment or like was given to or received by a peer. Regardless of their social engagement, participants received notifications from the app when they received a comment or a like from a peer. For this reason, given support was used for data analysis. Additional UP app features, including leaderboards and challenges, are described in depth elsewhere [36]. The overall study protocol was approved by the university's institutional review board, and all participants provided written informed consent.

\section{Data Analysis}

NVivo 11 Pro (QSR International) was used for qualitative analysis, and SPSS version 20 (IBM, Armonk, NK) was used for quantitative analysis. Descriptive analyses were conducted using means and frequencies for comments given and received. Furthermore, interquartile range (IQR) for given support (comments or likes given to peers) was used to identify superusers and lurkers because it approximated the participants' engagement with social features. Participants above the 75 th percentile in both social support categories (given likes and comments) were classified as superusers. Participants below the 25th percentile in both social support categories were classified as lurkers. For qualitative analysis, a combination of directed and conventional qualitative content analysis was used to analyze the app comments [37]. Codes were based on major social support constructs: emotional support, informational support, instrumental support, appraisal support, and self-talk $[10,13,14]$. Additional codes were developed through conventional qualitative analysis from reading through the comments. Moreover, 2 graduate-level investigators independently coded the comments, and agreement was determined using the NVivo software. Disagreement was settled through discussion and joint review of the comments among coders and the principal investigator (EL) who is a behavioral scientist. Due to protocol restrictions, no quotes from participants were abstracted from the app. Only the quantitative report and the coded qualitative themes are reported.

\section{Results}

\section{Descriptive Information}

Table 1 displays the baseline characteristics of the participants $(n=35)$. On average, participants had 8 peers (range 4-13) to socialize with over 12 weeks.

Throughout the study, there were 3153 likes and 1759 comments. The most likes received by one person was 524 , and the most comments were 291 with a median of 61 likes and 32 comments received. Of 35 participants, 3 did not receive a like or comment over the 12-week period. The median number of likes given was 2, with a range of 0 to 986 and an IQR of 40 . The median number of comments given was 14 , with a range of 0 to 344 and an IQR of 45 . The median number of self-talk comments given was 4, with a range of 0 to 232 and an IQR of 16. Moreover, $11 \%$ participants $(4 / 35)$ were above the 75 th percentile in given likes and comments. These 4 superusers combined accounted for $72.60 \%(2289 / 3153)$ and $51.28 \%$ $(902 / 1759)$ of the total likes and comments, respectively. Conversely, $17 \%$ participants (6/35) can be classified as lurkers because they were below the 25 th percentile of comments given, and they did not give any likes. The remaining 25 participants were classified as contributors-the likes or comments given were within the IQR. This group accounted for $27.40 \%$ (864/3153) likes and $48.72 \%(857 / 1759)$ comments. Lurkers had fewer peers (average: 6; range: 4-9) to communicate with throughout the 12 weeks than contributors (average: 8; range: 6-13) and superusers (average: 9; range: 8-11). Complete social 
support values for all participants are depicted in Table 2. The

reflects the participant's engagement with the social features.

likes and comments in the table reflect given support, as this

Table 1. Baseline demographic characteristics by study group ( $\mathrm{N}=35)$.

\begin{tabular}{llll}
\hline Characteristics & Intervention $(\mathrm{n}=19)$ & Wait-list control $(\mathrm{n}=16)$ & Total $(\mathrm{N}=35)$ \\
\hline Female, $\mathrm{n}(\%)$ & $16(84)$ & $13(81)$ & $19(83)$ \\
Ethnicity, $\mathbf{n}(\%)$ & & & $20(57)$ \\
$\quad$ Non-Hispanic white & $11(58)$ & $9(56)$ & $15(43)$ \\
$\quad$ & $8(42)$ & $7(44)$ & $22(63)$ \\
Other & $12(63)$ & $10(63)$ & $61.66(6)$ \\
Age, mean (SD) & $61.32(5)$ & $30.80(4)$ & $30.36(3)$ \\
Body mass index, $\mathrm{kg} / \mathrm{m}^{2}$, mean $(\mathrm{SD})$ & $29.99(3)$ & & \\
\hline
\end{tabular}

\section{Common Themes}

The comments within the app mostly followed the major social support constructs, as described in the Introduction section $[10,13,14]$. The only theme that was not prevalent was appraisal support. Some comments that were useful for self-evaluation were coded as a subtheme of emotional support. In addition to emotional support, other major themes included informational support, instrumental support, self-talk, and other theme. Each major theme had additional subthemes. Figure 1 illustrates the hierarchy of major and subthemes in the comments.

The intervention group participants gave more comments than the wait-list control group participants, but the most prevalent themes were the same between the 2 groups. Agreement between the 2 coders ranged from $53.4 \%$ to $99.4 \%$ for each theme. The lowest agreement was with self-talk $(67.9 \%)$ and emotional support (53.44\%). Table 3 displays the number of comments given by the participants per major theme. Several comments were coded into numerous themes. Emotional support was the most prevalent, followed by self-talk, other themes, informational support, and instrumental support.

Emotional support was further categorized as concern, gratitude, sharing, motivating, and social norms. Concern comments were those that expressed concern for their peer's health and well-being. Gratitude comments expressed thanks to fellow peers for their support. Sharing comments were conversation-like posts. Motivating comments were further categorized as congratulatory, encouragement, impressed, compliment, and verbal persuasion. Verbal persuasion were short, encouraging comments such as woo-hoo and yay. Social norms was further categorized as agreement and comparison.

Subthemes of self-talk included anecdote, feelings (positive and negative), planning, and reflection. Anecdotes were comments that shared personal information or a personal story but were not directed to a peer. Positive or negative comments toward an individual's own activity were coded as feelings. There were no negative comments between peers. Planning comments were the result of an individual planning future PA. Comments where an individual would reflect on their past PA or other health behaviors were coded as reflection.

Other themes were subcategorized as correction, technical problems, greeting, health behavior, and unknown. Users cannot edit a previous comment within the app; therefore, additional comments that fixed a previous comment were coded as a correction. Comments that expressed technical issues with the Up24 band or the app were coded as technical problems. Greeting comments were further subcategorized as welcome and salutation. Users had the option to also monitor their sleep and diet behavior, which were the 2 subthemes for health behavior. Finally, any other comments that could not be coded into the aforementioned themes were coded as unknown.

Informational support included informative and inquiry comments. Informative comments educated peers on PA, the app, or the Up24 band, and inquiry comments posed a question to peers. Instrumental support was further categorized as competition, exercise companion, and participatory support. Comments that mentioned an exercise companion differed from participatory support because the exercise companion was exercising with the individual's friend or family member, whereas participatory support came from discussing meeting for in-person exercise with their peers in the study. Participants were not expected to exercise with one another, but comments indicated that participants contacted one another and walked together on at least 12 occasions. All participatory support was organized in the app among the participants. 
Table 2. Participants' characteristics and social engagement ( $\mathrm{N}=35 ; 1-16$ were wait-list control participants, and 17-35 were intervention participants).

\begin{tabular}{|c|c|c|c|c|c|}
\hline No & Gender & Peers & Likes $(\mathrm{N}=3153), \mathrm{n}(\%)$ & Comments $(\mathrm{N}=1759), \mathrm{n}(\%)$ & Self-talk comments $(\mathrm{N}=758), \mathrm{n}(\%)$ \\
\hline $1^{\mathrm{a}}$ & $\mathrm{F}^{\mathrm{b}}$ & 10 & $299(9.48)$ & $166(9.43)$ & $31(4.1)$ \\
\hline $2^{\mathrm{a}}$ & $\mathrm{F}$ & 9 & $986(31.27)$ & $340(19.32)$ & $105(13.9)$ \\
\hline $3^{\mathrm{a}}$ & $\mathrm{M}^{\mathrm{c}}$ & 7 & $544(17.25)$ & $344(19.55)$ & $232(30.6)$ \\
\hline $4^{\mathrm{d}}$ & M & 6 & $2(0.06)$ & $0(0.00)$ & $0(0.0)$ \\
\hline $5^{\mathrm{d}}$ & $\mathrm{F}$ & 8 & $0(0.00)$ & $16(0.90)$ & $13(1.7)$ \\
\hline $6^{\mathrm{d}}$ & $\mathrm{F}$ & 8 & $0(0.00)$ & $4(0.22)$ & $2(0.3)$ \\
\hline $7^{\mathrm{d}}$ & $\mathrm{F}$ & 13 & $2(0.06)$ & $9(0.51)$ & $3(0.4)$ \\
\hline $8^{\mathrm{d}}$ & M & 10 & $1(0.03)$ & $5(0.28)$ & $3(0.4)$ \\
\hline $9^{\mathrm{d}}$ & $\mathrm{F}$ & 9 & $45(1.42)$ & $30(1.70)$ & $18(2.4)$ \\
\hline $10^{\mathrm{d}}$ & $\mathrm{F}$ & 9 & $0(0.00)$ & $1(0.05)$ & $1(0.1)$ \\
\hline $11^{\mathrm{d}}$ & $\mathrm{F}$ & 8 & $6(0.19)$ & $5(0.28)$ & $4(0.5)$ \\
\hline $12^{\mathrm{e}}$ & F & 7 & $0(0.00)$ & $0(0.00)$ & $1(0.1)$ \\
\hline $13^{3}$ & F & 8 & $0(0.00)$ & $0(0.00)$ & $0(0.0)$ \\
\hline $14^{\mathrm{e}}$ & $\mathrm{F}$ & 9 & $0(0.00)$ & $0(0.00)$ & $0(0.0)$ \\
\hline $15^{\mathrm{e}}$ & $\mathrm{F}$ & 4 & $0(0.00)$ & $0(0.00)$ & $0(0.0)$ \\
\hline $16^{\mathrm{e}}$ & F & 6 & $0(0.00)$ & $0(0.00)$ & $0(0.0)$ \\
\hline $17^{\mathrm{a}}$ & F & 11 & $460(14.58)$ & $52(2.95)$ & $26(3.4)$ \\
\hline $18^{\mathrm{d}}$ & F & 6 & $5(0.15)$ & $57(3.24)$ & $16(2.1)$ \\
\hline $19^{\mathrm{d}}$ & F & 6 & $24(0.76)$ & $223(12.67)$ & $82(11.2)$ \\
\hline $20^{\mathrm{d}}$ & M & 7 & $0(0.00)$ & $0(0.00)$ & $0(0.0)$ \\
\hline $21^{d}$ & F & 6 & $2(0.06)$ & $194(11.0)$ & $85(11.2)$ \\
\hline $22^{\mathrm{d}}$ & $\mathrm{F}$ & 6 & $5(0.15)$ & $40(2.27)$ & $14(1.8)$ \\
\hline $23^{d}$ & $\mathrm{~F}$ & 6 & $8(0.25)$ & $15(0.85)$ & $8(1.1)$ \\
\hline $24^{\mathrm{d}}$ & F & 11 & $0(0.00)$ & $76(4.32)$ & $38(5.0)$ \\
\hline $25^{\mathrm{d}}$ & M & 8 & $1(0.03)$ & $23(1.30)$ & $2(0.3)$ \\
\hline $26^{\mathrm{d}}$ & $\mathrm{F}$ & 6 & 338 (10.7) & $14(0.79)$ & $9(1.2)$ \\
\hline $27^{\mathrm{d}}$ & $\mathrm{F}$ & 6 & $13(0.41)$ & $17(0.96)$ & $12(1.6)$ \\
\hline $28^{\mathrm{d}}$ & $\mathrm{F}$ & 6 & $26(0.82)$ & $13(0.73)$ & $4(0.5)$ \\
\hline $29^{d}$ & F & 6 & $0(0.00)$ & $24(1.36)$ & $16(2.1)$ \\
\hline $30^{\mathrm{d}}$ & $\mathrm{F}$ & 8 & $279(8.84)$ & $46(2.61)$ & $17(2.2)$ \\
\hline $31^{\mathrm{d}}$ & M & 10 & $1(0.03)$ & $1(0.05)$ & $1(0.1)$ \\
\hline $32^{\mathrm{d}}$ & $\mathrm{F}$ & 13 & $40(1.26)$ & $4(0.22)$ & $0(0.0)$ \\
\hline $33^{\mathrm{d}}$ & $\mathrm{F}$ & 12 & $0(0.00)$ & $1(0.05)$ & $1(0.1)$ \\
\hline $34^{\mathrm{d}}$ & F & 10 & 66 (2.09) & 34 (1.93) & $14(1.8)$ \\
\hline $35^{\mathrm{a}}$ & $\mathrm{F}$ & 6 & $0(0.00)$ & $0(0.00)$ & $0(0.0)$ \\
\hline
\end{tabular}


${ }^{\mathrm{a}}$ Superuser.

${ }^{\mathrm{b}} \mathrm{F}$ : female.

${ }^{\mathrm{c}} \mathrm{M}$ : male.

${ }^{\mathrm{d}}$ Contributor.

${ }^{\mathrm{e}}$ Lurker.

Figure 1. Social support themes. The size of each box represents the prevalence of the different comment themes (not to scale). Study themes were developed based on the work of Heaney and Israel, Cavallo et al, and Cousins et al.

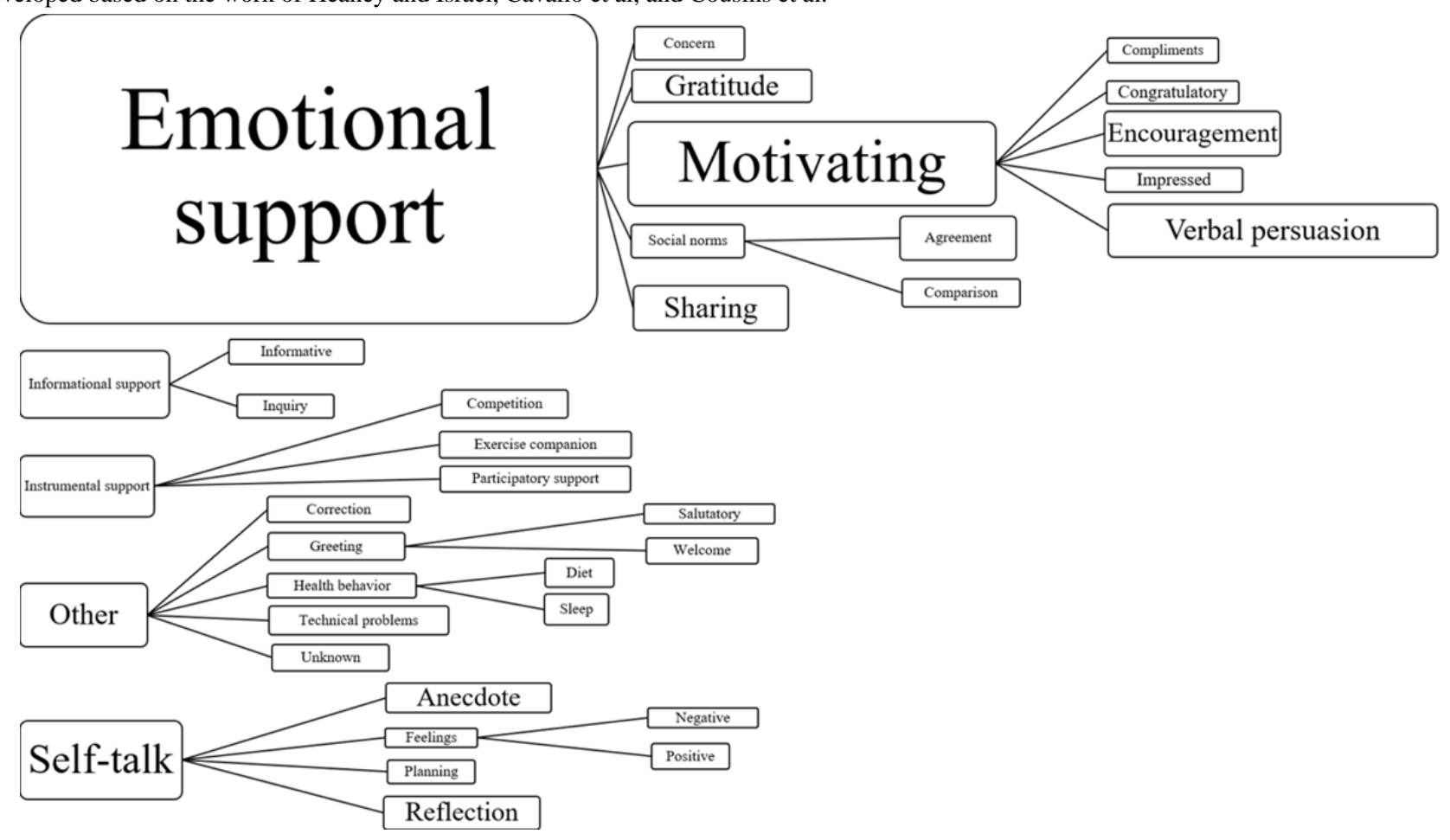


Table 3. Number of comments by themes.

\begin{tabular}{|c|c|c|c|}
\hline Themes & Intervention ( $\mathrm{n}=19$ participants) & Wait-list controls ( $\mathrm{n}=16$ participants) & Total participants $(\mathrm{N}=35)$ \\
\hline Emotional support $^{\mathrm{a}}, \mathbf{n}$ comments $(\%)$ & $475(50.6)$ & $596(67.3)$ & $1071(58.72)$ \\
\hline Concern $^{\mathrm{b}}$ & $29(3)$ & $24(3)$ & $53(3)$ \\
\hline Gratitude $^{\mathrm{b}}$ & $75(8)$ & $107(12.1)$ & $182(10.0)$ \\
\hline Motivating $^{\mathbf{b}}$ & $317(33.8)$ & $420(47.4)$ & 737 (40.4) \\
\hline Compliment $^{\mathrm{c}}$ & $41(4)$ & $54(6)$ & $95(5)$ \\
\hline Congratulatory $^{\mathrm{c}}$ & $53(6)$ & $60(7)$ & $113(6.2)$ \\
\hline Encouragement $^{\mathrm{c}}$ & $75(8)$ & $89(10)$ & $164(9.0)$ \\
\hline Impressed $^{\mathrm{c}}$ & $45(5)$ & $70(8)$ & $115(6.3)$ \\
\hline Verbal persuasion $^{\mathrm{c}}$ & $155(16.5)$ & $215(24.3)$ & $370(20.3)$ \\
\hline Sharing $^{b}$ & $92(10)$ & $80(9)$ & $172(9.4)$ \\
\hline Social norms ${ }^{b}$ & $42(5)$ & $18(2)$ & $60(3)$ \\
\hline Agreement $^{\mathrm{c}}$ & $13(1)$ & $5(1)$ & $18(1)$ \\
\hline Comparison $^{\mathrm{c}}$ & $32(3)$ & $13(2)$ & $45(3)$ \\
\hline Informational support ${ }^{\mathrm{a}}, \mathbf{n}(\%)$ & $64(7)$ & $18(2)$ & $82(5)$ \\
\hline Informative $^{b}$ & $23(2)$ & $2(0)$ & $25(1)$ \\
\hline Inquiry $^{b}$ & $40(4)$ & $17(2)$ & $57(3)$ \\
\hline Instrumental support ${ }^{\mathrm{a}}, \mathbf{n}(\%)$ & $48(5)$ & $11(1)$ & $59(3)$ \\
\hline Competition $^{\mathrm{b}}$ & $20(2)$ & $0(0)$ & $20(1)$ \\
\hline Exercise companion $^{\mathrm{b}}$ & $17(2)$ & $10(1)$ & $27(2)$ \\
\hline Participatory support ${ }^{\mathrm{b}}$ & $12(1)$ & $1(0)$ & $13(1)$ \\
\hline Self-talk ${ }^{a}, \mathbf{n}(\%)$ & $220(23.4)$ & $188(21.2)$ & $408(22.4)$ \\
\hline Anecdote $^{\mathrm{b}}$ & $83(9)$ & $85(10)$ & $168(9.2)$ \\
\hline Feelings $^{b}$ & $49(5)$ & $38(4)$ & $87(5)$ \\
\hline Negative $^{c}$ & $15(2)$ & $6(1)$ & $21(1)$ \\
\hline Positive $^{c}$ & $34(4)$ & $31(4)$ & $65(4)$ \\
\hline Planning ${ }^{\mathrm{b}}$ & $42(5)$ & $16(2)$ & $58(3)$ \\
\hline Reflection $^{b}$ & $98(10)$ & $78(9.0)$ & $176(9.6)$ \\
\hline Other $^{\mathrm{a}}, \mathrm{n}(\%)$ & $132(14.1)$ & $72(8)$ & $204(11.2)$ \\
\hline Correction $^{b}$ & $6(1)$ & $9(1)$ & $15(1)$ \\
\hline Greeting $^{b}$ & $23(2)$ & $24(3)$ & $47(3)$ \\
\hline Salutatory ${ }^{\mathrm{c}}$ & $10(1)$ & $11(1)$ & $21(1)$ \\
\hline Welcome $^{c}$ & $15(2)$ & $10(1)$ & $25(1)$ \\
\hline Health behaviors ${ }^{b}$ & $52(6)$ & $22(3)$ & $74(4)$ \\
\hline $\operatorname{Diet}^{c}$ & $7(1)$ & $0(0)$ & $7(0)$ \\
\hline Sleep $^{c}$ & $46(5)$ & $23(3)$ & $69(4)$ \\
\hline
\end{tabular}




\begin{tabular}{llll}
\hline Themes & Intervention $(\mathrm{n}=19$ participants $)$ & Wait-list controls (n=16 participants) & Total participants $(\mathrm{N}=35)$ \\
\hline Technical problems & & $16(2)$ & $49(3)$ \\
Unknown $^{\mathrm{b}}$ & $33(4)$ & $3(0)$ & $9(1)$ \\
Total comments $^{\mathrm{d}}$ & $6(1)$ & $885(48.5)$ & 1824 \\
\hline
\end{tabular}

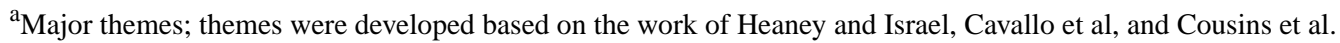

${ }^{\mathrm{b}}$ Submajor themes.

${ }^{\mathrm{c}}$ Minor themes.

${ }^{\mathrm{d}}$ Some comments were coded into several submajor or minor themes. Therefore, the total depicts the total number of comments under the major theme.

\section{Discussion}

\section{Principal Findings}

Our exploratory study on social support patterns of middle-aged and older adults using a mobile app found that without being mandated to socialize with other participants, the 35 participants who used the app as part of the intervention produced a total of 1759 comments and 3153 likes over a 12-week intervention period. Of 35 participants, 4 were classified as superusers because they were above the 75th percentile for all support categories (given likes and comments), whereas 6 participants were classified as lurkers for falling below the 25 th percentile in given comments and did not give any likes. Common themes coded from the content of comments followed constructs of social support, with the most prevalent comments classified as emotional support followed by self-talk.

Our evaluation partially supports the 90-9-1 principle in that the smallest portion of participants was superusers [24]; however, our sample did not follow the same distribution. We found that $17 \%(n=6)$ of participants were lurkers, $71 \%(n=25)$ were contributors, and $11 \%(\mathrm{n}=4)$ were superusers. Contributors were the largest group, which is contrary to the 90-9-1 principle that states lurkers are the most prevalent [24]. Despite the increase in superusers and contributors, their contribution in the app was similar to previous evaluations. Van Mierlo investigated the 90-9-1 principle in 4 digital health social networks and found that the superusers, the top $1 \%$, accounted for $73.6 \%$ of posts, whereas contributors accounted for $24.7 \%$ of posts [24]. In our study, superusers and contributors accounted for a comparable $72.6 \%$ and $27.1 \%$ of likes, respectively. The larger proportion of superusers and contributors in our sample may be the result of the intimate nature and anonymity of the study. At any given time during the study, there were only 1 to 10 peers for a participant to interact with versus the possible hundreds of peers on an SNS. It is unclear whether the size of the social group may have affected support provision behavior. However, too few peers may have inhibited social interaction and is a clear limitation of this exploratory investigation.

Previous research suggests that older adults are apprehensive to communicate with strangers [32]; the anonymous nature of the team may have also contributed to increased interactions in our study, as individuals were known by their icon rather than their real name. Some participants used these icons as a conversation starter, which helped to increase social engagement. This may have also affected the type of support that was provided. The anonymity did not result in negative comments toward peers, only in the form of self-talk. Participants may have been supportive because of their shared interests in the intervention or the surveillance of the intervention. Future research should investigate the effect of group size, anonymity, and icon personae on social interaction within apps or SNSs.

Although the number of comments varied between intervention and wait-list control participants, the most prevalent themes remained the same. The rank of themes by prevalence was emotional support, self-talk, other, informational support, and instrumental support. This trend is similar to that observed in women who used Fitbit and its Web-based social network [38]. A total of 20 women enrolled in a 6-week study were given a Fitbit Flex to monitor their activity and access to the Web-based Fitbit system. The social features of the Fitbit system included a message board for communication and a leaderboard [38]. The study found the most prevalent comments were motivational (emotional support), followed by sharing of PA ideas (informational support) and exercising with others (instrumental support). Self-talk and other types of comments were not reported. Results of the multilevel model analyses showed that social contact had a significant effect on PA, but it is unclear which type of support influenced PA the most [38].

Similar results were found in a PA intervention for individuals with Parkinson disease. Participants were given a Fitbit zip and assigned a peer mentor to help promote PA. The peer mentors were friends with the participants through the Fitbit system. As friends, the mentors were able to provide emotional support, through comments and likes, and instrumental support, through social comparison of activity. After an 8-week period of peer mentorship, participants increased their PA by $31 \%$ [39]. Yet, it is still unclear which type of support was driving the PA change. In traditional in-person social networks, emotional support has a considerable impact on PA compared with other types of support $[40,41]$. More research is needed to determine how PA is affected by each type of support (emotional support, instrumental support, informational support, and self-talk) within a virtual environment. Studies by Colon-Semenza et al and Arigo mandated social support, whereas this study did not [38,39]; researchers should also investigate the impact of mandated versus organic social engagement.

\section{Limitations}

The informed consent document did not ask for clearance to share comments from the app, as we did not expect virtual social support to be so prevalent. Furthermore, challenges related to 
the recruitment strategy of pilot trial should be considered in interpreting these data, as they caused the number of simultaneous peers to shift throughout the intervention period. Due to these limitations, this study is limited to a description and was not able to further examine the comments or their potential impacts on intervention effectiveness. The intervention was designed to impact PA behavior, which provides further limitations for this secondary data analysis. Participants' prior experience on social media use was not captured. As the inclusion of wait-list participants, change in PA as a result of social interaction could not be assessed. Therefore, our results are exploratory in nature, and no conclusions on the relationship of social support and PA could be made. Preliminary results from Arigo [38] and Colon-Semenza et al [39] suggest that more virtual social interaction results in more PA, but these studies were among young adults and Parkinson disease patients, respectively. These results are not necessarily generalizable to middle-aged and older adults. Furthermore, this study neither provides a network analysis of the relationship between lurkers, contributors, and superusers nor accounts for the fluctuating number of peers. This clear limitation of this study should be addressed in future trials by ensuring timely recruitment in small cohorts. Our thematic coding of the participants' comments was conducted independently by 2 coders following qualitative analysis guidelines, but an external researcher was not involved in the study to review the themes. This may limit the internal validity of our evaluation. Most of our participants were non-Hispanic white and female, and future research should include a more diverse sample. The strength of this study includes a thorough description of how older adults support their unknown peers using an app and evidence of the acceptability of anonymous social support in addition to counseling calls from research staff.

\section{Conclusions}

Use of wearable activity monitors that have a social networking feature is on the rise both commercially and in research $[38,42]$. Their features, similar to other SNSs, have the potential to make a widespread impact on PA promotion in the clinical and community settings. However, to our knowledge, use of the social networking features of these devices to provide social support are seldom reported or evaluated [30]. The results of our study suggest that middle-aged and older adults were willing to use social tools in a PA app to communicate with unknown, anonymous peers (total of 3153 likes and 1759 comments over 12 weeks). Social support in our study also happened organically without being required as a part of an intervention. Social support provided in the app followed constructs of social support [37]. The most prevalent type of support was emotional support. Contrary to the 90-9-1 principle, most participants were contributors $(71.4 \%)$, with only $11.4 \%$ superusers and $17.1 \%$ lurkers. In combination with the other implemented behavioral change techniques [4], our findings provide further support for the potential usefulness of wearable activity monitors as a promising intervention tool to encourage behavior change. Future research is needed to investigate the potential of these social support features to change PA behavior. Practitioners should be aware that these features exist in many available PA apps and may be used by patients to provide and receive support. However, education needs to be provided regarding information security.

\section{Acknowledgments}

This study was internally funded by the Claude D Pepper Older Americans Independence Center (grant number P30AG024832) and Sealy Center on Aging. Additional salary support was provided by the Cancer Prevention Research Institute of Texas (grant number RP140020); the National Institute on Disability, Independent Living, and Rehabilitation Research (grant number 90AR5009); a Mentored Research Scholar Grant in Applied and Clinical Research (grant number MRSG-14-165-01-CPPB) from the American Cancer Society; the American Heart Association (grant number 13BGIA17110021, 16PRE27090012); the National Institute of Child Health and Human Development (National Center for Medical Rehabilitation Research); the National Institute for Neurological Disorders and Stroke; and the National Institute of Biomedical Imaging and Bioengineering (grant number P2CHD065702).

\section{Conflicts of Interest}

None declared.

\section{References}

1. Keadle SK, McKinnon R, Graubard BI, Troiano RP. Prevalence and trends in physical activity among older adults in the United States: a comparison across three national surveys. Prev Med 2016 Aug;89:37-43 [FREE Full text] [doi:

10.1016/j.ypmed.2016.05.009] [Medline: 27196146]

2. Nyman SR, Victor CR. Older people's participation in and engagement with falls prevention interventions in community settings: an augment to the Cochrane systematic review. Age Ageing 2012 Jan;41(1):16-23. [doi: 10.1093/ageing/afr103] [Medline: 21875865]

3. Tate DF, Lyons EJ, Valle CG. High-tech tools for exercise motivation: use and role of technologies such as the internet, mobile applications, social media, and video games. Diabetes Spectr 2015 Jan;28(1):45-54 [FREE Full text] [doi: 10.2337/diaspect.28.1.45] [Medline: 25717278]

4. Lyons EJ, Lewis ZH, Mayrsohn BG, Rowland JL. Behavior change techniques implemented in electronic lifestyle activity monitors: a systematic content analysis. J Med Internet Res 2014 Aug 15;16(8):e192 [FREE Full text] [doi: 10.2196/jmir.3469] [Medline: 25131661] 
5. Eynon M, Foad J, Downey J, Bowmer Y, Mills H. Assessing the psychosocial factors associated with adherence to exercise referral schemes: a systematic review. Scand J Med Sci Sports 2019 May;29(5):638-650. [doi: 10.1111/sms.13403] [Medline: $\underline{30742334]}$

6. Greaves CJ, Sheppard KE, Abraham C, Hardeman W, Roden M, Evans PH, IMAGE Study Group. Systematic review of reviews of intervention components associated with increased effectiveness in dietary and physical activity interventions. BMC Public Health 2011 Feb 18;11:119 [FREE Full text] [doi: 10.1186/1471-2458-11-119] [Medline: 21333011]

7. Sarason IG, Levine HM, Basham RB, Sarason BR. Assessing social support: the social support questionnaire. J Pers Soc Psychol 1983;44(1):127-139. [doi: 10.1037/0022-3514.44.1.127]

8. Ståhl T, Rütten A, Nutbeam D, Bauman A, Kannas L, Abel T, et al. The importance of the social environment for physically active lifestyle--results from an international study. Soc Sci Med 2001 Jan;52(1):1-10. [doi: 10.1016/S0277-9536(00)00116-7] [Medline: 11144909 ]

9. Bors P, Dessauer M, Bell R, Wilkerson R, Lee J, Strunk SL. The Active Living by Design national program: community initiatives and lessons learned. Am J Prev Med 2009 Dec;37(6 Suppl 2):S313-S321. [doi: 10.1016/j.amepre.2009.09.027] [Medline: 19944930$]$

10. McAuley E, Jerome GJ, Elavsky S, Marquez DX, Ramsey SN. Predicting long-term maintenance of physical activity in older adults. Prev Med 2003 Aug;37(2):110-118. [doi: 10.1016/S0091-7435(03)00089-6] [Medline: 12855210$]$

11. Michie S, Richardson M, Johnston M, Abraham C, Francis J, Hardeman W, et al. The behavior change technique taxonomy (v1) of 93 hierarchically clustered techniques: building an international consensus for the reporting of behavior change interventions. Ann Behav Med 2013 Aug;46(1):81-95. [doi: 10.1007/s12160-013-9486-6] [Medline: 23512568]

12. Swartz MC, Lewis ZH, Swartz MD, Martinez E, Lyons EJ. Brief report: active ingredients for adherence to a tracker-based physical activity intervention in older adults. J Appl Gerontol 2019 Jul;38(7):1023-1034. [doi: 10.1177/0733464817739350] [Medline: 29165029]

13. Deci EL, Ryan RM. The 'what' and 'why' of goal pursuits: human needs and the self-determination of behavior. Psychol Inq 2000 Oct;11(4):227-268. [doi: 10.1207/s15327965pli1104 01]

14. Vallerand RJ. A hierarchical model of intrinsic and extrinsic motivation for sport and physical activity. In: Hagger MS, Chatzisarantis NL, editors. Intrinsic Motivation and Self-Determination in Exercise and Sport. Champaign, IL, US: Human Kinetics; 2007:356-363.

15. George M, Eys MA, Oddson B, Roy-Charland A, Schinke RJ, Bruner MW. The role of self-determination in the relationship between social support and physical activity intentions. J Appl Soc Psychol 2013 Apr 30;43(6):1333-1341. [doi: 10.1111/jasp.12142]

16. Heaney CA, Israel BA. Social networks and social support. In: Glanz K, Rimer BK, Viswanath K, editors. Health Behavior and Health Education: Theory, Research, and Practice. San Francisco, CA, US: Jossey-Bass; 2008:189-219.

17. Gibson AC, Foster C. The role of self-talk in the awareness of physiological state and physical performance. Sports Med 2007;37(12):1029-1044. [doi: 10.2165/00007256-200737120-00003] [Medline: 18027992]

18. Cousins SO, Gillis MM. 'Just do it... before you talk yourself out of it': the self-talk of adults thinking about physical activity. Psychol Sport Exerc 2005 May;6(3):313-334. [doi: 10.1016/j.psychsport.2004.03.001]

19. Cavallo DN, Tate DF, Ries AV, Brown JD, DeVellis RF, Ammerman AS. A social media-based physical activity intervention: a randomized controlled trial. Am J Prev Med 2012 Nov;43(5):527-532 [FREE Full text] [doi: 10.1016/j.amepre.2012.07.019] [Medline: 23079176]

20. de la Peña A, Quintanilla C. Share, like and achieve: the power of Facebook to reach health-related goals. Int J Consum Stud 2015 Aug 24;39(5):495-505. [doi: 10.1111/ijcs.12224]

21. McNeill LH, Kreuter MW, Subramanian SV. Social environment and physical activity: a review of concepts and evidence. Soc Sci Med 2006 Aug;63(4):1011-1022. [doi: 10.1016/j.socscimed.2006.03.012] [Medline: 16650513]

22. Woolley P, Peterson M. Efficacy of a health-related Facebook social network site on health-seeking behaviors. Soc Mar Q 2012 May 2;18(1):29-39. [doi: 10.1177/1524500411435481]

23. Nielsen J. Nielsen Norman Group. 2006. Participation Inequality: The 90-9-1 Rule for Participation Inequality in Social Media and Online Communities URL: http://www.nngroup.com/articles/participation-inequality/ [accessed 2019-05-19]

24. van Mierlo T. The $1 \%$ rule in four digital health social networks: an observational study. J Med Internet Res 2014 Feb 4;16(2):e33 [FREE Full text] [doi: 10.2196/jmir.2966] [Medline: 24496109]

25. Carron-Arthur B, Cunningham JA, Griffiths KM. Describing the distribution of engagement in an internet support group by post frequency: a comparison of the 90-9-1 principle and Zipf's law. Internet Interv 2014 Oct;1(4):165-168 [FREE Full text] [doi: 10.1016/j.invent.2014.09.003]

26. Ballantine PW, Stephenson RJ. Help me, I'm fat! Social support in online weight loss networks. J Consumer Behav 2011 Dec 23;10(6):332-337. [doi: $10.1002 / \mathrm{cb} .374$ ]

27. Edelmann N. Reviewing the definitions of 'lurkers' and some implications for online research. Cyberpsychol Behav Soc Netw 2013 Sep;16(9):645-649. [doi: 10.1089/cyber.2012.0362] [Medline: 23848960]

28. Hwang KO, Ning J, Trickey AW, Sciamanna CN. Website usage and weight loss in a free commercial online weight loss program: retrospective cohort study. J Med Internet Res 2013 Jan 15;15(1):e11 [FREE Full text] [doi: 10.2196/jmir.2195] [Medline: 23322819] 
29. Schlosser AE. Posting versus lurking: communicating in a multiple audience context. J Consumer Res 2005 Sep 1;32(2):260-265. [doi: $\underline{10.1086 / 432235]}$

30. Balatsoukas P, Kennedy CM, Buchan I, Powell J, Ainsworth J. The role of social network technologies in online health promotion: a narrative review of theoretical and empirical factors influencing intervention effectiveness. J Med Internet Res 2015 Jun 11;17(6):e141 [FREE Full text] [doi: 10.2196/jmir.3662] [Medline: 26068087]

31. Kullgren JT, Harkins KA, Bellamy SL, Gonzales A, Tao Y, Zhu J, et al. A mixed-methods randomized controlled trial of financial incentives and peer networks to promote walking among older adults. Health Educ Behav 2014 Oct;41(1 Suppl):43S-50S [FREE Full text] [doi: 10.1177/1090198114540464] [Medline: 25274710]

32. Immonen M, Sachinopoulou A, Kaartinen J, Konttila A. Using technology for improving the social and physical activity-level of the older adults. In: Wichert R, van Laerhoven K, Gelissen J, editors. Constructing Ambient Intelligence: Aml 2011 Workshops. Berlin, Heidelberg: Springer; 2012:201-205.

33. Pew Research Center. 2018. Social Media Fact Sheet URL: http://www.pewinternet.org/fact-sheet/social-media/ [accessed 2018-05-20]

34. Lyons EJ, Swartz MC, Lewis ZH, Martinez E, Jennings K. Feasibility and acceptability of a wearable technology physical activity intervention with telephone counseling for mid-aged and older adults: a randomized controlled pilot trial. JMIR Mhealth Uhealth 2017 Mar 6;5(3):e28 [FREE Full text] [doi: 10.2196/mhealth.6967] [Medline: 28264796]

35. Warburton DE, Bredin SS, Jamnik VK, Gledhill N. Validation of the PAR-Q+ and ePARmed-X+. Health Fitness J Can 2011;4(2):38-46 [FREE Full text] [doi: 10.14288/hfjc.v4i2.151]

36. Lewis ZH, Ottenbacher KJ, Fisher SR, Jennings K, Brown AF, Swartz MC, et al. Testing activity monitors' effect on health: study protocol for a randomized controlled trial among older primary care patients. JMIR Res Protoc 2016 Apr 29;5(2):e59 [FREE Full text] [doi: 10.2196/resprot.5454] [Medline: 27129602]

37. Hsieh HF, Shannon SE. Three approaches to qualitative content analysis. Qual Health Res 2005 Nov;15(9):1277-1288. [doi: 10.1177/1049732305276687] [Medline: 16204405]

38. Arigo D. Promoting physical activity among women using wearable technology and online social connectivity: a feasibility study. Health Psychol Behav Med 2015 Dec 31;3(1):391-409. [doi: 10.1080/21642850.2015.1118350]

39. Colón-Semenza C, Latham NK, Quintiliani LM, Ellis TD. Peer coaching through mhealth targeting physical activity in people with Parkinson disease: feasibility study. JMIR Mhealth Uhealth 2018 Feb 15;6(2):e42 [FREE Full text] [doi: 10.2196/mhealth.8074] [Medline: 29449201]

40. Seeman TE, Berkman LF, Charpentier PA, Blazer DG, Albert MS, Tinetti ME. Behavioral and psychosocial predictors of physical performance: MacArthur studies of successful aging. J Gerontol A Biol Sci Med Sci 1995 Jul;50(4):M177-M183. [doi: 10.1093/gerona/50a.4.m177] [Medline: 7614238]

41. Sherwood NE, Jeffery RW. The behavioral determinants of exercise: implications for physical activity interventions. Annu Rev Nutr 2000;20:21-44. [doi: 10.1146/annurev.nutr.20.1.21] [Medline: 10940325]

42. Lewis ZH, Lyons EJ, Jarvis JM, Baillargeon J. Using an electronic activity monitor system as an intervention modality: a systematic review. BMC Public Health 2015 Jun 24;15:585 [FREE Full text] [doi: 10.1186/s12889-015-1947-3] [Medline: $\underline{26104189]}$

\section{Abbreviations \\ IQR: interquartile range \\ PA: physical activity \\ SDT: self-determination theory \\ SNS: social networking site}

Edited by G Eysenbach; submitted 16.10.18; peer-reviewed by M Ehn, J Hawkins, D López López; comments to author 01.04.19;
revised version received 27.05.19; accepted 18.06.19; published 23.08.19
Please cite as:
Lewis ZH, Swartz MC, Martinez E, Lyons EJ
Social Support Patterns of Middle-Aged and Older Adults Within a Physical Activity App: Secondary Mixed Method Analysis
JMIR Aging 2019;2(2):e12496
URL: $\underline{\text { http:/laging.jmir.org/2019/2/e12496/ }}$
doi: $\underline{10.2196 / 12496}$
PMID: $\underline{31518281}$

(CZakkoyya H Lewis, Maria C Swartz, Eloisa Martinez, Elizabeth J Lyons. Originally published in JMIR Aging (http://aging.jmir.org), 23.08.2019. This is an open-access article distributed under the terms of the Creative Commons Attribution 
License (https://creativecommons.org/licenses/by/4.0/), which permits unrestricted use, distribution, and reproduction in any medium, provided the original work, first published in JMIR Aging, is properly cited. The complete bibliographic information, a link to the original publication on http://aging.jmir.org, as well as this copyright and license information must be included. 